\title{
Claves de la formación y el desarrollo humano en pedagogía
}

\author{
Keys on the Formation and Human Development in Pedagogy
}

\author{
Alixon David Reyes Rodríguez \\ Universidad Pedagógica Experimental Libertador \\ Instituto Pedagógico de Maturín \\ Maturín, Venezuela \\ alixdavid79@yahoo.com
}

Recibido 11 de mayo de 2012 • Corregido 20 de junio de 2012 • Aceptado 28 de junio de 2012

Resumen. El trabajo que a continuación se ofrece ha sido desarrollado desde la experiencia y la anécdota de quien ha compartido diversos espacios educativos pasando por todos y cada uno de los niveles del sistema educativo venezolano. Tal posibilidad es pensada como una plataforma importante a fin de comprender las ideas de formación y desarrollo humano presentes en la institucionalidad venezolana en el tránsito escolar. Creemos que la idea de formación que tenemos como educadores debe ser repensada en tanto esta pase por el crisol de las historias personales, por el crisol de los rostros de aquellos que con nosotros comparten su tiempo, su interés y su disposición de vida. Niños, jóvenes o adultos; todos tienen una identidad, tienen particularidades, diferencias, pero también coincidencias. Tanto el maestro como la escuela, el currículo y el Estado no pueden pensar una educación para alguien a quien no conocen, para alguien a quien no descifran. En este sentido, presentamos algunas reflexiones producto de un trabajo etnográfico partiendo, en primer lugar, de la convivencia escolar, entrevistas, análisis de clases, observaciones, registros anecdóticos, entre otros. Como resultado reflexionamos sobre varias categorías, a saber: formación, esperanza, diálogo, actitud y convivencia.

Palabras claves. Ética, formación, educación, esperanza, diálogo.

\footnotetext{
Profesor de Educación Física, Deporte y Recreación; Magíster en Enseñanza de la Educación Física; Doctor en Educación. Profesor ordinario de la Universidad Pedagógica Experimental Libertador. Coordinador general del Núcleo de Investigación en Pedagogía del Movimiento "Prof. Darwin Reyes" del Instituto Pedagógico de Maturín. Investigador becado por el Ministerio del Poder Popular para la Ciencia y la Tecnología. Miembro de la Confederación Iberoamericana de Medicina del Deporte. Actualmente Asesor del Ministerio del Poder Popular para las Comunas y Protección Social de la República Bolivariana de Venezuela. Es autor de las siguientes obras: Fraudes en el deporte. Los avatares de la disciplina entre una "cultura" de la hipocresía y el cosmopolitismo mundano; De la Educación; Léxico científicotécnico de la actividad física y sus afines; Filosofía de las religiones. Un ejercicio hermenéutico a través del relato del Rico y Lázaro; Gimnasia, Formación docente e integralidad. Hojas de "una" ruta para el encuentro y la proxemia; Sobre educación, política y algo más.
} 
URL: http://www.una.ac.cr/educare

\begin{abstract}
This paper is based on the experiences of the author, who has worked in the various levels of the Venezuelan educational system. This has been a very important platform to understand the ideas of education and human development within the Venezuelan institutionality in the educational field. The idea of education that we have, as teachers, should be rethought in order to consider the personal stories of those who share with us their time, interests and willingness: children, young people or adults, all with particular identities, differences and coincidences. The teachers, the schools and the State cannot consider an education for someone they do not know. In this sense, we provide some reflections resulting from our ethnographic work, based on the school life, interviews, class analysis, observations, and stories, among others. Our thoughts are classified as formation, hope, dialogue, attitude, and school life.
\end{abstract}

Keywords. Ethics, formation, education, hope, dialogue.

\title{
Introducción
}

Partimos de una premisa que se ha considerado crucial, a saber, las creencias determinan lo que somos, lo que pensamos, lo que enseñamos, el cómo lo hacemos, y por supuesto, el cómo vivimos. Esta cuestión inicial ofrece de partida la posibilidad de pensar lo educativo desde el campo de la filosofía, y es que, si no fuese así, sería harto complicado comprender el sustrato de nuestra formación.

Knight (2002) afirma que "existe una definida conexión entre las posiciones filosóficas y las prácticas educacionales. Lo que implica esta afirmación es que el fundamento de las prácticas educacionales está constituido por las creencias filosóficas" (p. 12). Conscientes de esta premisa, estamos convencidos del hecho de que ser lo que somos y el cómo somos ha estado influenciado por la educación recibida en el hogar y otros centros educativos tan convencionales, normativos y oficiales -curricularmente hablando-como la escuela y la universidad, y otros no tan convencionales (pero no por ello carentes de normatividad) tales como la iglesia -con un currículo especialmente preparado-, la calle, el grupo primario de amigos, los medios de comunicación, entre otros. Esas influencias -sean cuales fueren- están guiadas por un sustrato que casi nunca intentamos analizar, esto es, las creencias. Ahora bien, ¿qué tiene esto que ver con el asunto de la ética en lo educativo? Pues, sencilla y modestamente consideramos que la educación debe ser entendida en las claves ofrecidas por la ética. No se trata, entonces, de un asunto lógico, sino ético.

La perspectiva de la ética sobre la cual se ha de basar este trabajo se ancla en las variadas propuestas de Savater (2000, 1999, 1998), Pérez (2005, 2004), Skliar (2007), y Schiller (1954), entre las cuales se permea una especie de hilo conductor desde el ámbito de la pedagogía que asocia y acerca las posiciones, esto es, que armonizan en el encuentro conceptual de la ética a partir de la dimensión pedagógica. Ello no quiere decir que se 
soslaye la visión de la ética como filosofía moral. Es decir, hablamos de la ética como una experiencia relacional que favorece y permite el enriquecimiento de la humanidad como proyecto, al crear y producir más humanidad.

Para Savater (1998), la ética “(...) es una relación que intenta mantener el tú a tú, el cara a cara, el mantenerse frente a la mirada del otro, frente al reconocimiento del otro (...)” (p. 13), "(...) es una relación con personas, es una defensa de la persona (...)" (p. 16). Dice el mismo Savater (1998) "(...) La ética es un proyecto infinito, porque es el proyecto de la construcción de nuestra propia humanidad, y del apoyo a la humanidad de otros; y por lo tanto, no tiene límites, ni fin (...)" (p. 28). Es, pues, a este nivel de acercamiento, de proxemia humana, al cual nos referimos cuando hablamos y abordamos el tema de la ética.

\section{Metodología}

Esta investigación tiene un perfil eminentemente hermenéutico. La hermenéutica como método de investigación se ha hecho imprescindible en el contexto educativo gracias a los consecuentes planteamientos de Schleiermacher (1997), Heidegger (1958), Dilthey (1978), Husserl (1992), Ricoeur (1999), Lefebvre (1983) y Gadamer (1977).

Gadamer (1977) es quizás, dentro de los hermeneutas, el más connotado pensador. En su obra Verdad y método. Fundamentos de una hermenéutica filosófica, asoma la necesidad de la interpretación en la experiencia hablante con los textos y los individuos, para comprender la historicidad de la realidad y el valor que para ellos tiene la misma. Y esto último resulta fundamental en tanto el discurso hermenéutico no puede formalizarse, debido a que no existen últimas interpretaciones. Podemos pensar que su mayor aporte ha sido cimentar las bases para que la hermenéutica sea considerada como teoría y praxis en el complejo mundo de la interpretación crítica (Hurtado y Toro, 2007).

La pertinencia de la aplicación del enfoque hermenéutico, en esta oportunidad, se basa en la propiciación de bases para la interpretación crítica de varios testimonios -habida cuenta la naturaleza de esta investigación-, lo cual se enmarca en la contribución al desarrollo de una política deconstructiva y reconstructiva de ese tipo de experiencias testimoniales y de la impugnación de la tradición pedagógica dominante. Siendo así, se destaca la condición hermenéutica indispensable de la intersubjetividad para la subjetivación autónoma y dignificante de los individuos (Díaz, s. f.).

Con respecto a la característica etnográfica que se ha pretendido para esta investigación, podemos manifestar que se implementó la observación directa y la entrevista no estructurada como técnicas para la recolección de información, las cuales, sumadas a la proveniente de la investigación documental, han enriquecido mucho más el caudal y el 
URL: http://www.una.ac.cr/educare

sustrato de la información. Empleamos algunos rasgos del método etnográfico, por cuanto estos nos han permitido la práctica reflexiva con las personas sobre los fenómenos en estudio como resultado de la interacción, el intercambio, la expresión del ser y de aquello que le mueve a pensar o no pensar, hacer o no hacer, etc. Guber (2001) afirma que "(...) la investigación no se hace sobre la población sino con y a partir de ella, esta intimidad deriva, necesariamente, en una relación idiosincrática (...)" (p. 16). Pues, para esta investigación, la reflexión con las personas fue vital. Ello nos ayudó en el intento por entender lo que gira en torno a estas en el contexto de lo investigado. En ese orden también se expresa Tamayo (1999), cuando afirma que:

(...) La meta principal del método etnográfico consiste en captar el punto de vista, el sentido, las motivaciones, intenciones y expectativas que los actores otorgan a sus propias acciones sociales, proyectos personales o colectivos, y al entorno sociocultural que los rodea (p. 58).

Consideramos que el camino de la etnografía interpretativa ha sido fundamental para tratar el tema de la ética como signo interrogante de la formación; y más aún, cuando se trata de las creencias, de las subjetividades, de las relaciones dialógicas y de las concepciones que marcan el constructo teórico en la pedagogía, en quienes optan por la carrera docente y de la forma cómo asumen el fenómeno educativo en los espacios de formación académica.

Fue vital para esta investigación conocer el porqué de las prácticas convencionales en las aulas de clase y en las relaciones de los maestros y los alumnos, prácticas que surgen como resultado de concepciones de formación, distantes de las necesidades sociales. Quizás a esto que se ha dado en llamar etnografía, es lo que Habermas (2002) llamaba etnometodología en su Teoría de la acción comunicativa. Como ya se ha mencionado, entre los propósitos de esta investigación pudimos enfrentar tales concepciones, cuestionarlas y desmantelarlas, a fin de presentar una aaproximación en el marco de la concepción de la ética y sus relaciones implicantes con la formación.

Este estudio ha sido desarrollado desde la base de las conversaciones con los actores principales, a saber, alumnos, profesores, padres, representantes y directivos, además de que recurrimos a los registros y observaciones de clases, filmaciones, entre otros. Ello ha dado, como resultado, el levantamiento de información y el sustento de cinco categorías claves, las cuales serán desentrañadas a medida que avanzamos en el trabajo. Lo importante de ello es que estas categorías surgen del ideario de los involucrados, de sus creencias, asunto este que nos permite comprender entonces cuáles son algunas de las realidades y expectativas vividas por la gente en los espacios educativos convencionales. 
La investigación se ha realizado en varias instituciones ubicadas en zonas consideradas como de alto riesgo o como zona roja en la ciudad de Maturín (estado Monagas, República Bolivariana de Venezuela). Entre estas escuelas están: la Escuela Técnica Robinsoniana Maturín, la Escuela Básica Milá de la Rocá, y otras escuelas ubicadas en zonas irrumpidas por la invasión: La Puente y otros barrios como Morichal, Los Cocos, Prados del Sur, Moscú, Pinto Salinas, entre otros. Las entrevistas ascendieron a 44 en total (entre maestros, alumnos, directivos y representantes), 12 observaciones de clases, 12 registros, 6 filmaciones (autorizadas todas). Toda la información se ha manejado bajo estricta confidencialidad, habida cuenta la firma de una carta compromiso suscrita entre el investigador y los involucrados.

Finalmente, y partiendo de la información recabada, se procede a categorizar, a clasificar, y a comentar analíticamente cada uno de los elementos considerados relevantes.

Las categorías que tratamos surgen -como decíamos con anterioridad- de las inquietudes de la gente, de sus expectativas, de eso que creen los alumnos, los padres, los maestros, los directivos, etc. Esto ha sido posible gracias a un trabajo de carácter etnográfico en el cual se ha empleado la elaboración de entrevistas no estructuradas, de observaciones (a fin de contrastar algunas realidades), de recorridos por los pasillos y aulas de clase en varias escuelas, de la elaboración de registros anecdóticos, de filmaciones en varias situaciones, etc.

Las entrevistas realizadas parten de conversaciones con personas que, hemos considerado, ofrecen una perspectiva interesante en función del imaginario colectivo erguido en torno a la concepción de la ética y la formación. Estas conversaciones en algunos momentos toman caminos insospechados, caminos difíciles de sortear, pero son caminos que enriquecen el tema de investigación en tanto insertan elementos que fortalecen la propuesta (Reyes, 2012).

Guber (2001) deja entrever que es posible mantener hilos de conversación con varias personas en momentos diferentes en tanto se conserve la idea central y el propósito del diálogo. A su juicio, el tiempo y los tiempos del investigador, del entrevistado, de lo conversado, se negocian en la escritura, son los ires y venires de la palabra, palabra que no traiciona, palabra que no sucumbe. Para Guber (2001), los ritmos del encuentro entre estos tres elementos (investigador, entrevistado, la palabra) no deben estar determinados por el orden lógico, por la estructura de la entrevista, por los designios del dios cronos, por la secuencia. El tratamiento de la palabra, su utilización como herramienta discursiva, la posibilidad de enlazar el texto y las ideas, no deberían traicionar a la metódica del investigador en tanto se sugiera deslindarle de su propósito inicial. A veces, es más importante -incluso- un gesto que una palabra. 
URL: http://www.una.ac.cr/educare

Centro de interés

Ahora bien, iniciamos el trayecto mencionando que la ética es asumida en esta ocasión como una clave para la vida y como una clave para la humanización. Cuando hablamos de clave es porque hacemos referencia a la etiqueta de "imprescindible" que queremos otorgarle. No se trata, entonces, de cualquier tipo o estilo de vida, sino de uno que reconoce lo esencial del ser humano en su relación con el mundo y con los otros; se trata de esa ética que se diluye en las relaciones, en la vida que se vive y que se permea en todo lo que se hace, en todo lo que se dice, en todo lo que se piensa y en el cómo se piensa (esto es, el modo de pensar), en lo que se es. Hablamos de la ética en términos freireanos (Freire, 2004):

(...) De la ética universal del ser humano. De la ética que condena el cinismo (...) que condena la explotación de la fuerza de trabajo del ser humano, que condena acusar por oír decir, afirmar que alguien dijo A sabiendo que dijo B, falsear la verdad, engañar al incauto, golpear al débil y al indefenso, sepultar el sueño y la utopía, prometer sabiendo que no se cumplirá la promesa, testimoniar mentirosamente, hablar mal de los otros por el gusto de hablar mal. La ética de la que hablo es la que se sabe traicionada y negada en los comportamientos groseramente inmorales como en la perversión hipócrita de la pureza en puritanismo. La ética de la que hablo es la que se sabe afrontada en la manifestación discriminatoria de raza, género, clase. Es por esta ética inseparable de la práctica educativa, no importa si trabajamos con niños, jóvenes o adultos, por la que debemos luchar (...) (pp. 5-6).

El asunto de la educación reside, definitivamente, en que seamos mejores personas, mejores seres humanos cada día que pasa -y no nos referimos a ser mejor que los demás como si de una competencia se tratara-, que podamos transformarnos a cada instante en función de una humanización y de la humanidad. Pero, para ello, debemos comprender que, como maestros, el educar pasa por el andar y el caminar con el otro, escuchar al otro, entender al otro y entenderse con el otro y gracias al otro, darse y entregarse al otro. Ayudar a forjar la personalidad y la voluntad del ser humano con el cual tenemos la oportunidad y el privilegio de interactuar y compartir es ayudar al otro a descubrir sus potencialidades y posibilidades, fomentando su trascendencia y permitiendo que su esencia nos toque y nos conmueva de igual manera, y ello porque cuando formamos también somos formados, por ello cuando enseñamos también aprendemos (Reyes, 2011). La educación no puede prescindir de lo emotivo, de lo sensible, de lo afectivo, no puede prescindir de lo humano, del calor y del sentido de aquello que marca lo humano y que marca la diferencia. Como diría el maestro Pérez Esclarín, si queremos una educación efectiva, debemos tener una educación afectiva. 
Quizás uno de los mayores problemas de nuestra educación actual es que se ha suplantado lo eminentemente humano por lo literal y lo racional, por la tendencia del sistema y la lógica técnicoinstrumental. Hay una especie de miedo y pánico generalizado a lo humano, a lo reflexivo, a lo interpretativo, al logos. Pareciera que lo humano y lo espiritual se han convertido en especímenes de laboratorio, en bichos raros - ¿qué es eso?-, y pareciera ser una tétrica y paupérrima moda: no entendemos que lo técnico, lo científico, lo racional está garantizado, y ahora las preguntas que debemos hacernos es: de lo ético en la educación, ¿quién se encarga?; de lo estético de la formación, ¿quién se encarga?; de lo realmente importante, ¿quién se encarga?; lo más valioso, ¿quién lo asume?

Decir que lo técnico, lo científico, lo instrumental, lo operativo debe pasar a ser un asunto secundario en lo educativo, significa para muchos de los administradores de lo educativo -hoy, en Venezuela- (y esto sin intentos de generalizar, porque ciertamente existen quienes escapan a semejante distinción) una locura, y mientras, quienes así lo pensamos somos tildados con adjetivos innombrables, impronunciables. La retórica alcanza para mucho, incluso para disfrazar este tipo de actitudes. Ahora bien, de lo humano, ¿quién se encarga? Neill (1981) ya lo alertaba hace tanto: "a menos que nuestros planes educativos persigan el lograr individuos equilibrados, y no tan solo personas educadas, la educación seguirá siendo tan solo cuestión de mentes y no de corazones" (p. 10). Navarro (2011), a su tiempo sostiene fervientemente que:

(...) Los alumnos no van a la escuela a lo que creemos los maestros y las autoridades, a ellos sólo los mueven las emociones y en un momento secundario los aprendizajes, sin embargo las emociones tienen poca o nula cabida en las aulas (p. 08).

En este sentido, al percibir que lo que hacemos en las aulas de clase, muchas veces no encuentra correspondencia con las necesidades y las expectativas de las personas, es posible que, al analizar el asunto escolar y las relaciones en las aulas, la desesperanza nos embargue.

A continuación deseamos plantear algunas categorías que surgen desde la base del sustrato metodológico empleado. Cada una de las categorías ha sido agrupada y ofrecida habida cuenta la cercanía en las respuestas, las acciones develadas y los testimonios de las personas entrevistadas, observadas y filmadas. Partimos de una primera categoría: formación.

\section{Formación}

En conversaciones con varios profesores nos llamaba la atención el ideario que tienen con respecto a la premisa de la formación. Para la mayoría, la formación es equivalente a capacitación, instrucción y adiestramiento. Es decir, quien enseña Matemáticas supone que el alumnado está formado si aprende la tabla de multiplicar; en Literatura, si el muchacho o la muchacha es capaz de nombrar al autor de la novela en correspondencia con el nombre de la obra en cuestión. 
URL: http://www.una.ac.cr/educare

Una maestra nos decía: "ese muchacho está mal formado, no sabe leer". Le preguntaba: ¿y sobre cuál base afirma tal cosa? Su respuesta fue: "le doy un texto a leer y no sabe dónde hacer la pausa, tartamudea, entona inadecuadamente la acentuación...".

Un colega de Educación Física nos decía:

Ese muchacho es un flojo, ¿cómo cree que se va a formar? No quiere correr, no quiere aprender las reglas del juego, no se sabe las medidas de la cancha, ni el peso del balón. Pregúntele y se dará cuenta que no sabe quién inventó el voleibol.

Quizás sea una locura afirmar que no nos parece tan preocupante que el alumno presente estas fallas, consideramos más preocupante aún la idea de formación de los maestros y maestras. Tales respuestas nos permiten comprender que el ideario que se yergue en torno a la idea de formación está bastante enrevesado. No se trata de asumir como verdad absoluta la referencia del estudiantado, no obstante, permite acceder a ciertos elementos que podrían poner en tela de juicio la actitud con la cual el personal docente aborda el proceso de enseñanza, el aprendizaje e incluso sus relaciones con los estudiantes.

De acuerdo con las respuestas ofrecidas por el profesorado, la formación se remite exclusivamente a una memorización sin sentido, a la repetición, a la decodificación del lenguaje sin más, etc. ¿Por qué hablamos, entonces, de ética y formación? Pues, porque a juicio de quien escribe, precisamente el alma de lo educativo radica en el desarrollo de lo eminentemente humano, en el desarrollo de los valores que otorgarán significado a los contenidos -sean estos cuales fueren-.

Un jovencito que ha sido enviado en varias ocasiones a la oficina de Orientación de una escuela en la ciudad de Maturín, llorando nos decía: "A esos profesores no les importa nada más que su estúpida materia, no les importa si uno se muere o no, si uno asiste a clases o no, y si no asistes lo único que les importa de eso es la inasistencia, no el porqué no asististe".

Esta opinión nos llamó muchísimo la atención habida cuenta la edad del joven (15 años). Con esto no queremos decir que no pueda dar tal respuesta, sino que llama la atención en virtud de que es una respuesta bastante madura, cruda y realista para un joven de esa edad que, generalmente, creemos está pensado en otras cosas. La historia personal de este joven es bastante difícil, presenta magulladuras en su cuerpo, tatuajes variados, tiene perforaciones en las orejas, en la nariz y en la lengua, presenta excoriaciones en la piel y, por si fuera poco, muestra varias cicatrices de heridas producidas por armas cortantes. Sus padres fallecieron hace dos años (tomando esta fecha como referencia), en una balacera en medio de un allanamiento e intercambio de disparos con la policía. Por lo que se devela de su conversación y su aún permanencia en la escuela, percibimos que a pesar de todas las cosas que pudiesen suceder, él 
desea estudiar, lucha por mantenerse en la escuela, desea apartarse de una vida que, de seguro, no le ha deparado mayores oportunidades. Anhela estudiar y "salir adelante" (como él mismo lo manifiesta). "Dice: "No quiero morirme en las calles".

¿Qué es lo que más nos está preocupando en el aula de clases? ¿El contenido, el objetivo, la competencia, la utilidad del conocimiento?, ¿o quién está en capacidad de poseerlo? De la persona humana, ¿cuándo me acuerdo?, ¿cuándo la pongo en agenda? Lo decía Touraine (1996), cuando sostenía que "no se puede hablar de educación cuando el individuo queda reducido a las funciones sociales que debe asumir" (p. 274). Revisando este último caso, puede percibirse que el joven en cuestión es ampliamente permeable en cuanto a la posibilidad del diálogo, el acercamiento y la escucha, incluso desde el abordaje pedagógico, sin embargo, se ha estado perdiendo una valiosa oportunidad.

\section{Esperanza}

Mucha gente percibe la educación como una oportunidad. Esto es así, porque en algún rincón de su corazón tienen una esperanza, independientemente de cuál sea esta (empleo, profesionalización, riqueza, salida de la miseria, etc.). Pero si hay algo que debe reforzar la educación es, precisamente, la fuerza para soñar, para creer, para luchar. Una señora de la comunidad afirmaba:

Profe, mis tres primeros hijos trabajan como obreros (uno es maestro albañil y los otros dos le meten a todo), pero el último salió de abajo. Estudió como pudo en la universidad y no veo que pase las mismas necesidades de los otros, incluso los ayuda de vez en cuando, y a mí también. Es ingeniero y trabaja en PDVSA en el campo Morichal.

Otra señora nos decía muy angustiada: "Tuve que mudarme de Petare, porque me iban a terminar de matar a mis hijos. Me mataron a dos. Ellos no quisieron estudiar, lo reconozco, se dejaron convencer con los amigos de la cuadra y no los pude ayudar. El papá de los muchachos nos abandonó y me tocó criarlos sola, ellos hicieron cosas malas y la policía me los mató. Tuve que venirme, porque sino me los matan a toditos. Aquí trabajo como una negra, pero por lo menos tengo vivos y estudiando a los dos que me quedan".

Claro está, hay una manifestación de resiliencia estupenda, sin embargo, mayor es la carga de esperanza, no solo por la posibilidad de superación personal y logro académico, sino por la ocasión de educar a dos hijos en condiciones totalmente diferentes, hijos que vivan y que vivan bien, sin el acoso y la zozobra de los anteriores. 
De una forma u otra (repito: independientemente del tipo de esperanza), la educación está siendo vista por mucha gente como una esperanza y se cree que logrando la inclusión y asegurando el trayecto completo en el proceso de escolarización, finalmente se alcanzarán las metas propuestas inicialmente. En estas respuestas observamos a una madre que quiere que su hijo "salga de abajo", es decir, que se titule, que logre un buen empleo y tenga ingresos para subsistir dignamente supliendo sus necesidades. Otra señora ve en la educación la tabla de salvación de sus otros dos hijos.

Este asunto se convierte en un asunto ético (y práctico de la moral), cuando el personal docente intenta ( $y$ de hecho a veces lo logra) hacer ver al alumnado como fracasado (independientemente de sus disposiciones y posibilidades), cuando algunos maestros pretenden minimizar a sus estudiantes a través de un ejercicio desmedido de autoridad, al creerse dueños o dueñas de dotes de sabiondos y de cuasi iluminados.

Invitamos a pensar y a reflexionar en: ¿para qué sirve la educación entonces?, ¿qué piensan los maestros y maestras? Aunque sabemos que las actitudes déspotas no son propiedad de la mayoría, ¿cómo hacemos para ayudar a quienes sí padecen tal condición?, ¿estamos coadyuvando a que el proceso formativo responda a estas necesidades de la gente?

Debe quien se dedica a la enseñanza ser optimista, y ese optimismo se traduce en esperanza; debe ser diferente, en tanto la educación puede llegar a ser la clave para derrotar la desesperanza, la impotencia y la frustración. Y hablamos de esperanza por cuanto es esta el oxígeno necesario para vivir; hablamos de esperanza porque es esa una de las mayores necesidades de la gente en tiempos tan problemáticos y difíciles en la historia de la humanidad. Los padres miran la sociedad y se preocupan al notar las condiciones morales, políticas, económicas, espirituales, sociales, ideológicas, en las que les tocará criar a sus hijos; los grupos de docentes se asustan ante el vandalismo circundante en las escuelas y ante el libertinaje promovido y vendido por los medios masivos de dizque comunicación; las iglesias se alarman ante la barbarie de la maldad y el auge de conductas desenfrenadas; las personas votantes se pasman ante la inexistencia de candidatos creíbles y ante la generalidad de la corrupción, la mentira y el engaño, al punto de que ya la palabra corrupción se endilga como sinónimo de político.

Es duro perder la esperanza, porque quien la pierde, pierde sus motivos de vida, no tiene nada que esperar de ella. Por esto, desde el optimismo, preferimos creer y considerar que la educación provee de ocasiones para retomar el camino perdido; la educación promueve el cambio del orden artificial y actual de las cosas y, en tanto sea así, ella, definitivamente, debe bañarse y basarse en la esperanza: sin ello, no es educación, sino una absurda y barata propaganda política. Freire (2000) lo plantea en estos términos: "enseñar exige la convicción de que el cambio sí es posible" (p. 25), y eso es lo que hay que decirle a la gente, que sí es posible, que es difícil, pero que también es posible y necesario, y quizás por ser difícil, es riesgoso. Pero a pesar de ello hay que decirle a la gente que sí se puede vivir, hay que decirle a la gente que sí vale la pena seguir luchando, seguir viviendo, seguir esperando de forma activa, hay que decirle a la gente que sí se puede crecer, hay que enseñarle a la gente que sí es posible educar y formar, hay que decirle y enseñarle a la gente que sí se puede trabajar, hay que decirle y enseñarle a la 
gente que sí es posible ser diferentes, hay que decirle y enseñarle a la gente que sí es posible transformar esta sociedad y nuestras condiciones de vida: sí es posible amar y perdonar. Debemos plantear, de acuerdo con Jares (2005):

Educar desde y para la esperanza. Especialmente necesaria y relevante en estos tiempos de incertidumbre, de precarización material y espiritual, de vandalización [sic] de las relaciones sociales, de institucionalización creciente en la vida política de la mentira y el desencanto, del uso del miedo como estrategia política, de cuestionamiento del papel de la educación (...) proponemos llevar pedagogía a la esperanza y ésta a aquella (...) No puede haber esperanza sin pedagogía ni pedagogía sin esperanza. La educación, en todas sus formas y contextos, debe tener conciencia moral, tomar partido por el futuro y dar esperanza. Por ello estamos profundamente convencidos y confiados en el papel de la esperanza para encarar el futuro. Es obvio que no es la panacea que vaya a resolver todos los problemas sociales, pero tampoco es menos cierto que sin su concurso no hay futuro posible. (pp. 22-23)

\section{Diálogo pedagógico}

Heidegger (1958) sostiene que "enseñar es más difícil que aprender porque enseñar significa: dejar aprender" (p. 20). En función de ese diálogo que debe reinar en el ambiente de clases muchos jóvenes nos decían cosas como éstas:

-Es que ese profesor no deja hablar.

- La tipa esa cree que es la única que sabe.

-Una profesora me dijo el otro día que si yo no sabía que eran los buenos modales que ella me los iba enseñar (gritándome delante de todo el mundo).

-En los consejos de los profesores [consejos de curso] lo único que hacen es hablar mal de uno, pero ni siquiera se le acercan a decirle que lo que está haciendo es bueno o malo.

Cuando amas dejas aprender, hablar, pensar a la otra persona, incluso, la dejas equivocarse, cuando amas al otro le permites su espacio, le dejas ir, le sueltas, y ya, le permites y le ofreces el diálogo, generas condiciones para ello, pero el diálogo visto no como intercambio de información o comunicación, sino como la disposición a escuchar y a desarrollar la posibilidad de entenderse mutuamente respetando posturas, decisiones e ideas, cuando amas le dejas hacer su camino y eso sí que es bastante. 
Margalit, citada por Mèlich (2003), confía en que el “(...) educar es también dar espacio y tiempo al otro, es reconocerle al otro el derecho a cometer sus propios errores por grandes que sean (p. 43); cuando dejas aprender y das espacio y tiempo al otro individuo, enseñas a vivir, enseñas al vivir, enseñas para el vivir; educar es pasión que obra, pasión que quema, pasión que toca, pasión que forma, que transforma, que diferencia y que hace la diferencia; pasión que humaniza cada vez más el acto pedagógico y que humaniza al humano proyectándole en la posibilidad inacabada de llegar a SER humano, de llegar a ser lo que se es (en términos Nietzscheanos); es ofrecer oportunidades, abrir posibilidades, generar condiciones, enseñarle al indefenso a defenderse y a desenvolverse en la vida diaria. Es, en términos Freireanos, acercar a la persona y darle la posibilidad de que se libere de las tinieblas y la opresión, es ayudarle a liberar su conciencia, a preguntar y a preguntarse, a cuestionar y a cuestionarse, a comprender y a buscar el por qué o el para qué de las cosas, para que se desarrolle, para que asuma una posición en la vida y la comprenda para ser coherente, para que ofrezca lo mejor de sí en cada esfuerzo y tarea, para que se comprometa con el corazón...

\section{Actitud docente y programas educativos}

Se les pregunta al grupo de jóvenes: ¿saben por qué y para qué se les enseña tal cosa? La mayoría responde así: "Bueno, imagino que es porque eso es lo que manda el ministerio?, ¿no?". Esta respuesta (categorizada por ser muy común) revela la necesidad de consustanciar y consolidar el elemento decisorio en la formación de la niñez y la juventud, y-entiéndase bien- no se pretende dejar sembrada la duda con respecto a cuáles deben ser los contenidos de la enseñanza, sino en el tono en el que se desarrollan y en el cómo se enseñan en las aulas y ambientes de clases.

Podría parecer ingenuidad, pero resulta curiosa la matriz de opinión que intenta despolitizar el hecho educativo, como que si una educación política fuese similar a la fabulesca hydra. El hecho educativo jamás es neutro, siempre responde a una concepción y a una intención que se permea desde el currículo y desde la imposición y asunción de un discurso, entre otras aristas. Obviamente, una educación política representa una dimensión compleja por cuanto abre espacio para la dialéctica, permite la diversidad, la pluralidad, permite la diferencia y la divergencia, la comprensión de los cambios y las transformaciones, el ejercicio pleno de los derechos públicos y privados, y ello no tiene por qué representar un escándalo.

Es increíble, pero la connotación de la palabra POLÍTICA es realmente nefasta. Parece ser, desde hace mucho tiempo, un sinónimo de corrupción, partidismo, clientelismo. No obstante, tenemos un sisma en la formación, al carecer esta de alma y sentido de proyecto de país (de cualquier país), cuando carece de alma y sentido de proyecto personal, cuando carece de alma y sentido de nación. ¿Por qué se supone que debemos aprender lo que aprendemos?, ¿por qué eso y no otra cosa?, ¿están conformes los grupos de jóvenes con la educación que reciben?. Pues, por las respuestas recibidas parece que 
no. ¿Tienen elementos como para disentir, para mostrar su desacuerdo? Obviamente no. Claro que hay inconformidad, bien sea porque el estudiantado cree que "no está saliendo bien preparado para acceder a niveles superiores de la educación" (una de las varias respuestas dadas), o bien sea porque considera que no hay elementos suficientes que le permitan debatir, plantear posturas diferentes, desarrollar otros contenidos, leer otros libros, otros autores, entre otras cosas.

Los maestros escasamente estamos dando oportunidades reales o generando condiciones manifiestas e implícitas en el acto educativo para el libre pensar, para discutir. No hay muchas garantías para despertar credibilidad y generar confianza en los alumnos cuando quienes están administrando programas educativos ni siquiera son profesionales del área de la educación, o cuando quienes administran tales programas en las aulas de clase están faltando a sus responsabilidades reales con pasmosa impunidad. Una jovencita cursante de un $6^{\circ}$ año de la especialidad de Petróleo sostenía: "Profe, lo que yo creo que pasa es que el profesor ese que nos da la materia no sabe más de allí, por eso tiene que seguir dando eso".

\section{El problema de la convivencia en la educación}

¿Estamos fomentando la convivencia?, ¿estamos trabajando en las relaciones humanas o en el manejo efectivo de conflictos? A veces creo que lo que estamos desarrollando con nuestro alumnado en las aulas de clases, son plataformas para la competencia fratricida, para la intolerancia. $Y$ eso pasa mucho por la conducta del mismo maestro o maestra, incluso por quien dirige las instituciones.

El presidente del Centro de Estudiantes de una escuela nos comentó: "El director no habla con nosotros a menos que cerremos los portones, y cuando lo hace viene molesto por el cierre de los portones y nos amenaza con llamar a la policía". Por otra parte el director manifiesta: "Esos muchachos son unos malandros, groseros, son unos bárbaros, no respetan, quieren resolver los problemas a la fuerza. Cuidado y te queman el carrito al salir de aquí". A lo que le respondo:

-No se preocupe, no tengo carro por ahora -a lo que él riposta-.

-Bueno, cuidado y te secuestran.

Le pregunto al director: “¿Ha tratado de entablar mesas de diálogo y negociación con los muchachos?, ¿han nombrado una comisión interdisciplinaria con presencia estudiantil para sentarse a resolver los problemas de la institución?". Él responde tajantemente:

- Con ellos no sirve nada de eso. 
URL: http://www.una.ac.cr/educare

No se cree que la acción estudiantil sea la adecuada al cerrar los portones, no se está legitimando semejante conducta. No es poca cosa en una institución educativa. No obstante, la parte dirigente tampoco asume una postura acorde con la ocasión, independientemente del cierre de los portones y del estacionamiento de la institución.

Obviamente, con esa conducta ninguna de las dos partes podrán resolver nada, pues lo único que intentan hacer es atacarse por separado. No hay espacio para la convivencia, y decimos que no lo hay porque a ese estado de alarma pulsante y constante no puede llamársele convivencia. Convivencia existe cuando se vive CON el otro, cuando se está JUNTO al otro, no cuando se está en CONTRA del otro; convivencia existe cuando a pesar de las diferencias existe la tolerancia. Pero, vistas las cosas, en el caso presentado no se dan las condiciones para generar el encuentro, no se ofrecen garantías para un acercamiento a pesar de que las circunstancias que les unen son comunes, no hay espacio para la proxemia. Savater (1998), sostiene:

(...) No se puede formar solamente a las personas desde el punto de vista laboral; formarles para que sepan apretar botones o para que cumplan funciones más o menos gestoras, sin haberles formado la capacidad de convivencia y ciudadanía, que no surge naturalmente de las personas. Los demócratas no surgen de las piedras naturalmente, como las flores silvestres; hay que cultivarlos, regarlos (...). (p. 181)

Como se ha venido tratando el tema, este pequeño papel de trabajo nos permite recoger algunas conclusiones iniciales habida cuenta que aún sigue siendo un papel en construcción. De alguna manera se cree que el asunto de la ética pasa por ser una cuestión pedante, de posiciones puritanas, de comportamientos moralistas, posmodernos, de conductas perfectas y propias de monasterios. Sin embargo, pensamos que muy distante de ello, la ética como marca que impregna la vida humana y las relaciones, se deja ver en aquellas cosas que definen al ser que finalmente somos, a las personas que somos. Y esto se refleja en lo que sucede a diario en las aulas de clases, en las relaciones con los estudiantes y los demás compañeros de trabajo. Es válido y necesario acotar que la idea del presente trabajo (evidentemente en una primera entrega), no es el de colocar el accionar docente en tela de juicio, sino confrontar y cuestionar la praxis pedagógica en función de aquellas cosas que sustentan nuestras teorías y nuestras representaciones o creencias en el ámbito pedagógico. La idea es que ello permita el análisis y la seria reflexión sobre lo que hacemos a diario en las aulas de clase y, por supuesto, más aún con aquellas actitudes que confirman, consolidan o debilitan la relación entre el alumnado y quienes le enseñan. 
A continuación ofrecemos algunas de las conclusiones a las cuales llegamos en la ocasión:

1. La concepción de formación que tienen el profesorado entrevistado se corresponde con lo que se ha evidenciado en los registros de las actividades y clases observadas. Se opta por la memorización y la repetición de contenido como fórmula para el aprendizaje. Esta situación causa la pérdida de oportunidades para el desarrollo de propuestas verdaderamente formativas en las que se privilegie el desarrollo de valores, la necesidad del compromiso educativo, la virtud de la experiencia y el trabajo, la aventura del pensamiento, la confrontación con problemas educativos reales, la identificación con problemáticas sociales, entre otras cosas.

2. Padres y madres, representantes, y no pocos estudiantes perciben la educación como una esperanza en algunas localidades en las que las condiciones de vida representan una limitante para la prosecución de los estudios y para la dedicación futura.

3. La oportunidad para el diálogo pedagógico está latente en los ambientes de aprendizaje, no obstante tal condición, no se está aprovechando la apertura. El intercambio de información inconexa con los aconteceres de la vida produce desazón en varios estudiantes, que bien dicho sea de paso, esperan una actitud diferente por parte de sus docentes. Una joven que está por egresar-, nos decía: "Queremos un maestro, no un sabiondo arrogante". Ya, tal opinión, deja mucho que pensar en cuanto a la actitud de algunos maestros, quizás más preocupados por la lectura de su largo currículum vitae que por sostener relaciones afables, respetuosas y conducentes al éxito en el aprendizaje en el hecho educativo.

4. Es preciso revisar, en comunión, los contenidos de la enseñanza para no vaciar de sustento el proceso formativo. Si bien es cierto que un joven de 15 años difícilmente tendrá una percepción clara sobre lo que necesita aprender, bien vale la pena contrastar sus sentires, podría ser que, en parte, estemos equivocados. Además, esta idea que se conecta con la acotación del ítem anterior, pasa por pensar que la actitud docente al momento de abordar la escena educativa debe ser repensada en tanto se trata de una relación de carácter humano entre maestro (a) y alumno (a).

5. El asunto de la convivencia y la tolerancia en los espacios educativos debe ser materia de discusión cotidiana, habida cuenta de la oleada de violencia escolar que se manifiesta mundialmente. Este es un problema que tiene una matriz en el hogar, no obstante, se termina manifestando en el entorno escolar amenazando con expandir su radio de acción. Por ello, tanto el personal de dirección, como docentes, alumnado y demás personal de las instituciones educativas, en unión, deberán acometer comisiones, formar equipos de trabajo, desarrollar líneas estratégicas de acción para fortalecer el proceso formativo que, a diario, se desarrolla en las aulas. 
URL: http://www.una.ac.cr/educare

6. Todos estos elementos (formación, esperanza, diálogo, actitud docente, programas educativos, convivencia) forman parte de una idea terminal de formación y desarrollo humano conveniente de ser pensada y desarrollada en el espectro escolar. Pero más allá de tan solo ser pensada, debe ser asumida con niveles máximos de compromiso, por cuanto creemos que tributan a esa ideario ofrecido originalmente por Savater (1998) al hacer referencia a lo ético (que no la moral).

Se habla de la sumatoria de estos elementos como un signo interrogante de la formación y el desarrollo humano, porque sigue siendo el punto flaco de nuestros servicios educativos. Todo esto más allá de que eso se sepa hasta la saciedad; más allá, incluso, de que en el elemento de la retórica sea desarrollado con vehemencia, porque sigue siendo la cara de la moneda que al caer en la mano cae de vuelta sobre el sello. Es la ética como punto de reunión -de la formación, la esperanza, el diálogo, la actitud docente, la convivencia-, el signo interrogante de la formación y el desarrollo humano, porque trasciende el tratamiento curricular, deberá entender el maestro que una relación dialógica pasa por ser el piso sobre el cual se podrán construir las bases para el aseguramiento del éxito escolar y personal del alumnado; es la ética, como punto de reunión e inflexión, un signo interrogante, en tanto concebimos la formación y el desarrollo humano en palabras mayúsculas, es decir, una formación que trasciende a lo meramente disciplinar, a lo técnico, a lo administrativo, para atender lo más importante: lo humano de lo humano.

Mucha gente se va de las aulas de clases con vidas cargadas de frustración, sin posibilidades de respuesta para cambiar su realidad, sin posibilidad para cambiar su mundo, para transformarlo. Siempre he pensado que, antes de ser profesor de Educación Física, soy maestro, y que, además, el solo hecho de estar frente a otro, con otro y junto a otro ya es para mí un privilegio. ¿Cómo no ha de ser entonces la ética una clave para el entendimiento?, ¿cómo hago para responsabilizarme de los otros, por ellos y con ellos?, ¿cómo pienso lo que hago cotidianamente si tengo 30 o 40 personas a diario conmigo compartiendo un espacio de su vida?, ¿por qué intento transformar e impactar sus vidas sin ni siquiera conocerles?, ¿permito acaso que ellos impacten la mía?, ¿cómo es posible poder trascender al currículo si no me permito que sus identidades y sus particularidades permeen la mía?, ¿qué termina siendo más importante y determinante en la praxis pedagógica: el contenido curricular, o el contenido humano de quien está frente a mí?

La ética debe seguir siendo el reto supremo y el verdadero desafío de la educación venezolana, pero la ética no como problema de la filosofía moral, sino como estilo de vida asumido. Así ha sido siempre. Son estas algunas de las reflexiones que surgen de estas cuestiones que venimos esbozando y desarrollando en esta investigación que, como se ha dicho, aún está en desarrollo. 


\section{Referencias}

Díaz, P. J. (s. f.). Hermenéutica y Educación: Por una estrategia para la comprensión lectora no reproductiva y la constitución de comunidades interpretativas. (Centro de Investigaciones Contemporáneas UPEL-Maracay). Maracay, Venezuela: Editorial Corona.

Dilthey, W. (1978). Sección de obras de Filosofía. Obras de Dilthey. México: Fondo de Cultura Económica.

Freire, P. (2004). Pedagogía de la autonomía. Sao Paulo: Paz e Terra.

Freire, P. (2000). Pedagogía de la indignación (3a ed). Madrid: Morata.

Gadamer, H. G. (1977). Verdad y método. Fundamentos de una hermenéutica filosófica. Salamanca: Sígueme.

Guber, R. (2001). La etnografía: Método, campo y reflexividad. Colombia: Grupo Editorial Norma.

Habermas, J. (2002). Teoría de la acción comunicativa (Volumen I). México: Taurus.

Heidegger, M. (1958). ¿Qué significa pensar? Buenos Aires, Argentina: Nova.

Hurtado, I. y Toro, J. (2007). Paradigmas y métodos de investigación en tiempos de cambio. Caracas: Los libros de El nacional.

Husserl, E. (1992). Invitación a la fenomenología. España: Editorial Paidós.

Jares, X. (2005). Educar para la verdad y la esperanza (2a ed.). España: Editorial Popular.

Knight, G. (2002). Filosofía y Educación. Colombia: APIA.

Lefebvre, H. (1983). La presencia y la ausencia. Contribución a la teoría de las representaciones. México: Fondo de Cultura Económica

Mèlich, J-C. (2003). La sabiduría de lo incierto. Sobre ética y educación desde un punto de vista literario. Educar, 31, 33-45.

Navarro S., J. (julio-septiembre, 2011). Editorial. Revista Educ@rnos, 1(2), 7-8. Recuperado de http:// revistaeducarnos.com/sites/default/files/educ@rnos2.pdf.

Neill, A. S. (1981). Corazones, no solo cabezas en la escuela (4ª ed). México: Editores Mexicanos Unidos.

Pérez, A. (2005). Más y mejor educación para todos. Caracas, Venezuela: Editorial San Pablo.

Pérez, A. (2004). Educar para humanizar. Madrid: Nárcea ediciones.

Reyes, A. (2011). Filosofía de las religiones. Alemania: Lap Lambert \& Editorial Académica Española. 
Reyes, A. (2012). Teoría de la recreación: Claves para su resignificación (Tesis Doctoral). Universidad Pedagógica Experimental Libertador, Instituto Pedagógico de Maturín. Maturín, Venezuela.

Ricoeur, P. (1999). Historia y narratividad. España: Editorial Paidos.

Savater, F. (2000). Ética para Amador (35ª ed). Bogotá, Colombia: Editorial Planeta Colombiana.

Savater, F. (1999). Las preguntas de la vida. Barcelona: Editorial Ariel.

Savater, F. (1998). Ética y ciudadanía. Caracas, Venezuela: Monte Ávila Editores.

Schiller, F. (1954). La educación estética del hombre. Madrid: Espasa Calpe.

Schleiermacher, F. (1997). Los discursos sobre hermenéutica. Cuadernos de Anuario Filosófico. España: Universidad de Navarra.

Skliar, C. (2007). La educación (que es) del otro. Argumentos y desierto de argumentos pedagógicos. Argentina: Noveduc.

Tamayo M. (1999). La investigación: Módulo 2. (3ª ed.). Bogotá, Colombia: Instituto Colombiano para el fomento de la Educación Superior.

Touraine, A. (1996). ¿Podremos vivir juntos? Buenos Aires, Argentina: Fondo de Cultura Económica. 